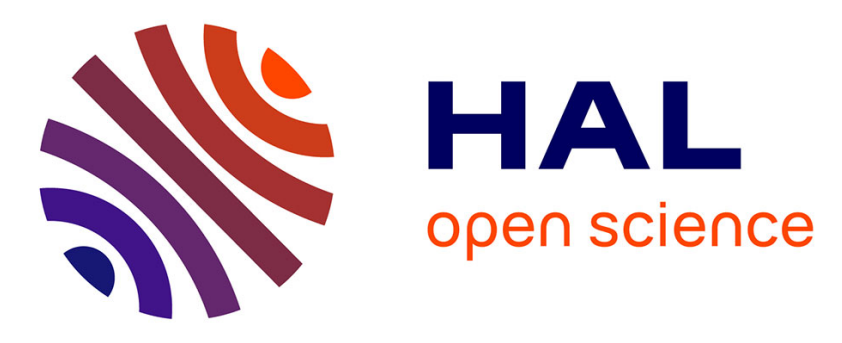

\title{
Analysis of chlordecone by LC/MS-MS in surface and wastewaters
}

Nicolas Cimetiere, Sylvain Giraudet, Marie Papazoglou, Hélène Fallou, Abdeltif Amrane, Pierre Le Cloirec

\section{- To cite this version:}

Nicolas Cimetiere, Sylvain Giraudet, Marie Papazoglou, Hélène Fallou, Abdeltif Amrane, et al.. Analysis of chlordecone by LC/MS-MS in surface and wastewaters. Journal of Environmental Chemical Engineering, 2014, 2 (2), pp.849 - 856. 10.1016/j.jece.2014.01.010 . hal-01016599

\section{HAL Id: hal-01016599 \\ https://hal.science/hal-01016599}

Submitted on 30 Jun 2014

HAL is a multi-disciplinary open access archive for the deposit and dissemination of scientific research documents, whether they are published or not. The documents may come from teaching and research institutions in France or abroad, or from public or private research centers.
L'archive ouverte pluridisciplinaire HAL, est destinée au dépôt et à la diffusion de documents scientifiques de niveau recherche, publiés ou non, émanant des établissements d'enseignement et de recherche français ou étrangers, des laboratoires publics ou privés. 


\title{
Analysis of chlordecone by LC/MS-MS in surface and wastewaters
}

Nicolas Cimetiere $^{\mathrm{a}, \mathrm{b}, 1}$, Sylvain Giraudet ${ }^{\mathrm{a}, \mathrm{b}}$, Marie Papazoglou ${ }^{\mathrm{a}, \mathrm{b}}$, Hélène Fallou, ${ }^{\mathrm{a}, \mathrm{b}}$, Abdeltif Amrane $^{\mathrm{a}, \mathrm{b}, \mathrm{c}}$, Pierre Le Cloirec $\mathrm{c}^{\mathrm{a}, \mathrm{b}}$

${ }^{a}$ Ecole Nationale Supérieure de Chimie de Rennes, CNRS, UMR 6226, 11 Allée de Beaulieu, CS 50837, 35708 Rennes Cedex 7, France

${ }^{\mathrm{b}}$ Université européenne de Bretagne

${ }^{c}$ Université de Rennes 1, 263 Avenue du Général Leclerc, Campus de Beaulieu, CS 74205, 35042 Rennes Cedex

\begin{abstract}
Chlordecone (also known as Kepone) was used extensively in the French West Indies until 1993. This persistent pollution raises the question of the faith of this pesticide through water treatment plants and its eventual release in the environment. To address this issue, a two-step methodology is herein proposed. First, a complete description of the analysis of CLD is given using liquid chromatography with mass spectrometry (LC/MS-MS). The reliability of this analytical methodology was demonstrated in ultrapure water as well as in the presence of organic and/or inorganic compounds (groundwater, river water and nutritive solutions). The limits of quantification were decreased to $1.5 \mu \mathrm{g} \mathrm{L}^{-1}$. In a second part, the removal of CLD is considered via the sorption onto activated sludge. Kinetics and isotherms of sorption were determined. Very short times (less than $5 \mathrm{~min}$ ) were observed to reach the equilibrium. Moreover, a linear relationship was determined for the sorption equilibrium, which led to the conclusion that the solid/liquid partition coefficient was $7600 \mathrm{~L} \mathrm{~kg}^{-1}$, i.e. $\log K_{\mathrm{OC}}$ of 3.88 , very close to the values encountered for the sorption of CLD in soils.
\end{abstract}

\section{Keywords}

\footnotetext{
${ }^{1}$ Corresponding author

Email address: nicolas.cimetiere@ensc-rennes.fr; (+33) 223238015
} 


\section{Introduction}

Chlordecone (CLD), also commercially known as Kepone, Merex, or Curlone, is an organochlorinated pesticide extensively used in Guadeloupe and Martinique islands (French West Indies) from 1971 to 1993 in order to protect banana plantation against weevil attack. CLD is a toxic and persistent pollutant. Moreover delayed and cumulative effects were suggested [1]. CLD dosage in banana fields was estimated to $3 \mathrm{~kg}_{\text {year }}{ }^{-1} \mathrm{ha}^{-1}$ and concentrations up to $10 \mathrm{mg} \mathrm{kg}^{-1}$ are currently observed in contaminated area [2]. Twenty years after this organic compound was banned, contaminated agricultural zones have become the new diffuse source of CLD. Rainfall and soil leaching leads to CLD diffusion from the soil to the aquatic system. Concentrations of chlordecone up to $1 \mu \mathrm{g} \mathrm{L}^{-1}$ and $0.5 \mu \mathrm{g} \mathrm{L}^{-1}$ have been observed in surface and drinking waters, respectively. Due to its hydrophobicity, chlordecone was frequently associated with particulate matter in river and sediments; recently Bocquene and Franco [3] have reported CLD concentrations up $57 \mu \mathrm{g} \mathrm{kg}^{-1}$ in Martinique river sediments. Numerous studies, dedicated to the CLD determination in various matrixes has been conducted since 1960. Electron capture gas chromatography (GC-ECD) has become a technique of choice for the determination of CLD in water [4] and [5], soil and sediments [5], [6] and [7] food [8] and biological tissues [9] and [10]. More recently gas chromatography equipped with mass spectrometry has also been employed for CLD determination (GC-MS). The advantage of MS or MS-MS detection over ECD in environmental samples is the lower sensitivity to matrix effects [11]. Moreover GC-MS allows the simultaneous determination of organochlorinated with other pesticides classes [12] and [13]. At this stage GC-ECD and GC-MS for the determination of chlordecone can be considered as reliable methods even if some drawbacks remain. For instance, heavy preparations before measurements are required (liquid/liquid or solid-phase extraction, clean up procedures, ...). Moreover CLD in water samples must be transferred in a compatible phase for GC injection. High pressure liquid chromatography (HPLC) allows the injection of aqueous samples with limited preparation. To our knowledge, one paper reports the determination of CLD by liquid chromatography with UV detection [14], but, in this study, the low molar extinction coefficient of CLD, the quantification of CLD is limited to the $\mathrm{mg} \mathrm{L}^{-1}$ level [14]. More recently, the quantification of CLD was carried out using a liquid chromatograph equipped with a mass spectrophotometer [15]. But, very few details were given in this article on the analytical methodology. Especially, the impact of the matrix (organic matters, minerals) was not assessed even though these compounds are well-known for disturbing the analysis.

Besides, the CLD is a pesticide that needs to be removed from wastewaters prior to their release in the environment. Wastewater treatments are most often based on biodegradation but for pesticides, these treatments might be inefficient. Some anaerobic microorganisms are able to use a wide variety of organic halogenated compounds (including polychlorinated biphenyl and dioxin) as electrons acceptor. Thus, a wide variety of aromatic chlorinated compounds are biodegradable, mainly by an anaerobic pathway [16] and a high number of chlorine atoms is not a problem for anaerobes, which use chlorinated compounds as final electrons acceptor following a 
process named dehalorespiration [17], [18] and [19]. Since this reductive dechlorination is an important environmental microbial process, it can be asked if chlordecone is really refractory to microbial assimilation [20]. Indeed, there is a lack of recent studies dealing with CLD biodegradation owing to its prohibition since more than thirty years in the US, and hence most of the related studies were carried out before 1990. Few studies are available and are only dealing with the oxidation in anaerobic conditions, involving some specific microbial species. In vitro CLD dechloration was observed in the presence of B12 vitamin [21] and [22]. Likewise, in vivo CLD dechloration in methanogenic conditions had been shown using Methanosarcina thermophila species [23]. The results of Jablonski et al. have been also recently confirmed on wastewater from Guyana containing $2 \mathrm{mg} \mathrm{L}^{-1}$ CLD [2].

From these studies, CLD is likely to be refractory to any microbial attack in aerobic conditions. For urban and agricultural wastewaters, the anaerobic ways of biodegradation, with dedicated microorganism species, are too specific and do not constitute reliable options for treatments of large flow rates, with low CLD concentrations (typically at the $\mu \mathrm{g} \mathrm{L}^{-1}$ level). Therefore, another approach consist of using the biosorption onto activated sludge as the separation process [24] and [25]. Biosorption experiments have already shown interesting results for chlorinated organic pollutants: lindane [26] and [27], 2,4-dichlorophenol [28] and [29], pentachlorophenol [27] or 2-chlorobiphenyl [27]. The results obtained for the lindane are particularly interesting since lindane is a hexachlorocyclohexane, which is the closest pesticide to CLD in terms of chemical structure. Aksu, in 2005, reviewed the potential applications of biosorption for the removal of organic pollutants and, concerning lindane, adsorption capacities ranged from 0.5 to $2.8 \mathrm{mg} \mathrm{g}^{-1}$ [30]. However, times to reach the sorption equilibrium were long from $4 \mathrm{~h}$ to 3 days. The biosorption uptakes could be attributed to the cell walls of the biomass and the octanol/water partition coefficient was the main property driving the uptakes of these organic compounds onto live and dead biomasses [27]. Similarly, hydrophobic interactions and van der Waals forces were predominant during the biosorption of lindane on two types of bacteria (gram-negative: Escherichia coli, Zooglea ramigera and gram-positive: Bacillus megaterium, B. subtilis) [26].

The objectives of this study were, firstly, to develop and certify the analysis of CLD using the LC/MS-MS technique and, secondly, to determine the sorption capacities of CLD onto activated sludge. On one hand, the analysis of CLD has to be lowered to trace levels (i.e. $\mu \mathrm{g} \mathrm{L}^{-1}$ ) and to be confirmed in complex matrices (in the presence of natural organic matter and inorganic compounds). On the other hand, an application of this analytical methodology was carried out for the quantification of the CLD sorbed on activated sludge, as well as the trace concentration remaining in the aqueous phase. Sorption kinetics and equilibria were assessed using the developed method.

\section{Materials and methods}

\section{Chemicals and reagents}


Standards of chlordecone (CLD) were obtained from Fluka (pestanal ${ }^{\circledR}$, analytical standard), chlordecone was dissolved in acetonitrile (ACN) (chromasolv ${ }^{\circledR}$ Plus, for HPLC, $\geq 99.9 \%$; SigmaAldrich) or ultra-pure water (UPW) (Milli-Q, Millipore corporation, $18.2{\mathrm{M} \Omega \mathrm{cm}^{-1}}^{-}$). Stock solutions of CLD $500 \mathrm{mg} \mathrm{L}^{-1}$ in ACN or $1 \mathrm{mg} \mathrm{L}^{-1}$ in UPW were prepared by weighing and then dissolving in the appropriate solvent. Working standard or experiment solutions were prepared by dilution from stock solutions, standard stock solutions in ACN were stored in the dark at $4{ }^{\circ} \mathrm{C}$ and aqueous solution were freshly prepared before experiments. Aqueous solutions of CLD was assumed to be stable since no significant decrease of CLD concentration was observed during two months without precaution (opened 201 bottle exposed to ambient light at room temperature).

\section{Procedure}

Particulate matter must be eliminated from the solution before LC analysis in order to protect analytical column and detector, $0.2 \mu \mathrm{m}$ pore size membrane is recommended for UPLC applications. Aqueous solution of chlordecone was filtrated onto various membranes (cellulose acetate, GHP-polypropylene) and the residual concentration of chlordecone was determined in the permeate solution in order to evaluate adsorption of CLD onto the membrane surface. GHP and cellulose acetate filters were purchased from Pall Corporation and Sartorius, respectively.

$0.2 \mu \mathrm{m}$ filters (from Sartorius) were used to filtrate sample, with diameters of 12.5, 25 and $47 \mathrm{~mm}$. Additional experiments were carried out with $0.2 \mu \mathrm{m}$ filters of cellulose acetate, which have diameters of 25 and $47 \mathrm{~mm}$. These membranes were placed into a 25 or $47 \mathrm{~mm}$ stainless steel filter holder, aqueous solution of chlordecone was then filtrated into the membrane. Flow rate $\left(1 \mathrm{~mL} \mathrm{~min}^{-1}\right)$ was controlled with a syringe pump, exact permeate volume was determined by weighting. Elution of membrane was carried out with various ACN:UPW composition ranging from 0:100 to 100:0 (v:v). Successive aliquots of $3 \mathrm{~mL}$ were sampled and the CLD concentration was determined by UPLC/MS-MS; samples were eventually diluted with ACN:UPW (50:50 $(\mathrm{v}: \mathrm{v}))$ if expected concentration excess the linearity range.

\section{Analytical apparatus}

Analysis of the extract was carried out using a Waters (Aquity UPLC) liquid chromatographic system equipped with a mass spectrometer detector (Quattro Premier; Micromass). $5 \mu \mathrm{L}$ were injected (full loop mode) into a BEH-C18 chromatographic column $(100 \mathrm{~mm} \times 2.1 \mathrm{~mm} \mathrm{ID}$, $1.7 \mu \mathrm{m}$ ) eluted at $400 \mu \mathrm{L} \mathrm{min}^{-1}$ in isocratic condition (ACN:UPW, 50:50, v:v). The pH of the eluent was adjusted to 2 with formic acid (FA) and oven column was set at $45{ }^{\circ} \mathrm{C}$. Complete calibration curves were performed at the beginning and at the end of the sample set, the mean slope value of these curves was used in order to quantify samples. Moreover, middle range standard was determined all the 10 injections in order to evaluate MS-MS signal stability relative deviation of MS-MS signal during analytical run was lower than $5 \%$. 
Electrospray ionization (ESI) source was used as interface between LC system and mass spectrometer. Source temperature and voltage are important factor in the MS signal, and its effect must be evaluated carefully. Preliminary experiments were conducted in order to determine the operating conditions, stock solution of CLD in ACN was infused in the ESI source within ACN:UPW; 50:50 mobile phase, best parameters were found in negative mode (ESI-) for a cone temperature and a voltage equal to $120^{\circ} \mathrm{C}$ and $40 \mathrm{~V}$, respectively. Chlordecone full-scan mass spectra were obtained in the range $m / z=400-600$ at a scan rate of $10 \mathrm{scan} \mathrm{s}^{-1}$; characteristic ion corresponding to $[\mathrm{M}+\mathrm{OH}]^{-}$was observed at $m / z=507$ ( Fig. 1a); similar result was obtained by Moriwaki and Hasegawa [31]. Mass spectrum obtained with acidified mobile phase at a cone voltage equal to $40 \mathrm{~V}$ exhibit the adduct ion $[\mathrm{M}+\mathrm{HCOOH}+\mathrm{OH}]^{-}$centered at $\mathrm{m} / \mathrm{z}=553$ according to theoretical isotopic mass distribution ( Fig. 1). Mass spectrum obtained from the fragmentation of the $m / z=507$ ion is shown in Fig. $1 \mathrm{~b}$ with a collision cell voltage of $20 \mathrm{~V}$ and exhibit a major daughter ion at $\mathrm{m} / \mathrm{z}=427$. LC/MS/MS acquisition was performed in the single reaction monitor $(\mathrm{SRM})$ mode by following the reactions $\mathrm{m} / \mathrm{z}=507 \rightarrow 427$, characteristic of chlordecone.

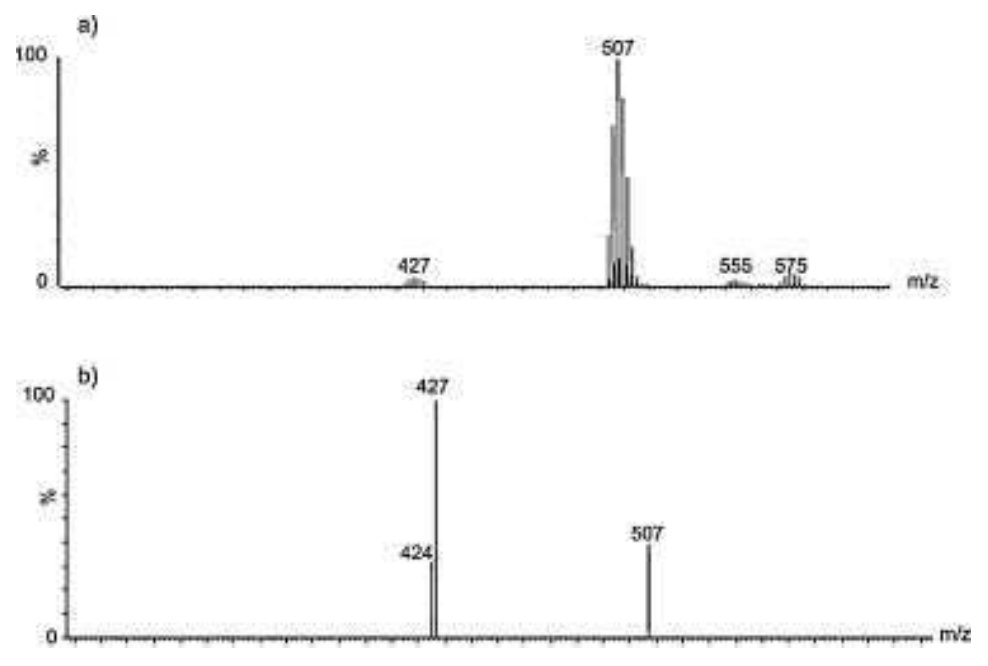

Fig. 1. (a) Chlordecone full-scan mass spectra; (b) mass spectrum obtained from the fragmentation of the $\mathrm{m} / \mathrm{z}=507$ ion.

\section{Activated sludge}

Activated sludge was collected from the aeration tank of the wastewater treatment plant of Beaurade (Rennes, France). The collected activated sludge was incubated in a laboratory scale activated sludge reactor without the target substance. The reactor was continuously aerated and was maintained at room temperature. 
Daily, $1 \mathrm{~g}$ of the following mixture was added in the activated sludge reactor: $0.64 \mathrm{~g}$ peptone, $15.2 \mathrm{~g} \mathrm{NH}_{4} \mathrm{Cl}, 0.11 \mathrm{~g} \mathrm{~K}_{2} \mathrm{HPO}_{4}, 140 \mathrm{~g} \mathrm{CH}_{3} \mathrm{COONa}$. Once a month $200 \mu \mathrm{L}$ of Viandox (Unilever, France) were added in order to diversify carbon sources in the medium.

When needed, sludge samples were taken from the incubation reactor and were then used for experimental purpose. Prior to the experiment, it was centrifuged (4000 rpm for $5 \mathrm{~min}$ ) and washed at least three times using tap water in order to remove the residual carbon and mineral sources of the maintenance media.

\section{Sorption}

Chlordecone is a stable molecule with a low solubility in water and which easily accumulate in organic matter [32].

To examine its sorption behavior, $0.2 \mathrm{~g} \mathrm{~L}^{-1}$ of activated sludge was added to $500 \mathrm{~mL}$ of a $1 \mathrm{mg} \mathrm{L}^{-1}$ CLD solution, which was beforehand autoclaved for inactivation $\left(121^{\circ} \mathrm{C}\right.$ for $\left.20 \mathrm{~min}\right)$. Sampling was performed every $5 \mathrm{~min}$; the supernatant of centrifugation $(0-4000 \mathrm{rpm}$ in $20 \mathrm{~s}$ and then $30 \mathrm{~s}$ at $4000 \mathrm{rpm}$ ) was then recovered as fast as possible. Experiments were duplicated. To perform sorption isotherms, activated sludge in a range of concentrations between 0.025 and $2 \mathrm{~g} \mathrm{~L}^{-1}$ was added to $500 \mathrm{~mL}$ of a $1 \mathrm{mg} \mathrm{L}^{-1} \mathrm{CLD}$ solution.

\section{Results and discussion}

\section{Chlordecone analysis in aqueous phase}

\section{Effect of filtration}

Preliminary experiments have been made in order to select chromatographic conditions for the chlordecone determination. In UPW, the best conditions for the separation on BEH-C18 column and ionization of CLD were $70 \%$ ACN-30\% UPW acidified with $0.1 \%$ FA at $45^{\circ} \mathrm{C}$. In these conditions retention time for CLD was $1.2 \mathrm{~min}$. In order to avoid any clogging of the analytical column and detector capillary suspended matter need to be removed prior to the chlordecone analysis. Using $1.7 \mu \mathrm{m}$ particle size analytical column it was recommended to use filters with $0.2 \mu \mathrm{m}$ pore size. Due to the apolarity of chlordecone, a potential adsorption of CLD into these organic membranes was suspected. $10 \mathrm{~mL}$ of aqueous CLD $\left(100 \mu \mathrm{g} \mathrm{L}^{-1}\right)$ was filtered through cellulose acetate (Sartorius, $12.5 \mathrm{~mm} ; 0.2 \mu \mathrm{m}$ ) or polypropylene (GHP, Pall Corporation; $12.5 \mathrm{~mm} ; 0.2 \mu \mathrm{m}$ ) filters and CLD concentration was measured in the permeate.

Results showed that chlordecone was quantitatively adsorbed onto organic membranes (Fig. 2). In order to avoid analytical bias due to the sample filtration two solutions were considered: (i) the saturation of membrane filtration prior to the analysis; (ii) the addition of a co-solvent (acetonitrile, methanol, ...) to avoid the adsorption of CLD via competition effects or better 
affinities with the solvent. Pre-saturation of filters was evaluated in order to determine the breakthrough curve of CLD and the minimum volume needed to limit the adsorption effect. $1 \mathrm{~L}$ of CLD $\left(100 \mu \mathrm{g} \mathrm{L}^{-1}\right.$ in UPW) was filtered onto the organic membranes at a flow rate of $1 \mathrm{~mL} \mathrm{~min}^{-1}$; permeate was fractionated in $100 \mathrm{~mL}$ aliquots and chlordecone concentration was determined by LC-MS/MS. Fig. 2 shows the CLD concentration in the permeate as a function of total filtered volume. These results show that CLD of all permeate samples was low $\left(<5 \mu \mathrm{g} \mathrm{L}^{-1}\right)$ compared to the initial concentration $\left(100 \mu \mathrm{g} \mathrm{L}^{-1}\right)$. At the beginning a CLD leak was observed during the filtration onto cellulose acetate membrane whereas CLD concentration in the permeate sample was not significant with polypropylene filters. In spite of the initial leakage observed with cellulose acetate filters, no significant increasing of CLD concentration was observed in permeate with the increasing of total filtered volume $\left([\mathrm{CLD}] /[\mathrm{CLD}]_{0} \approx 0.05\right)$. In the case of polypropylene filters a slow increase of CLD concentration was observed, and CLD concentration in permeate sample reached $6 \mu \mathrm{g} \mathrm{L}^{-1}$ after $1 \mathrm{~L}$ of total volume filtered. These results show that the saturation of the membrane could not be easily reached using a simple pre-filtration step.

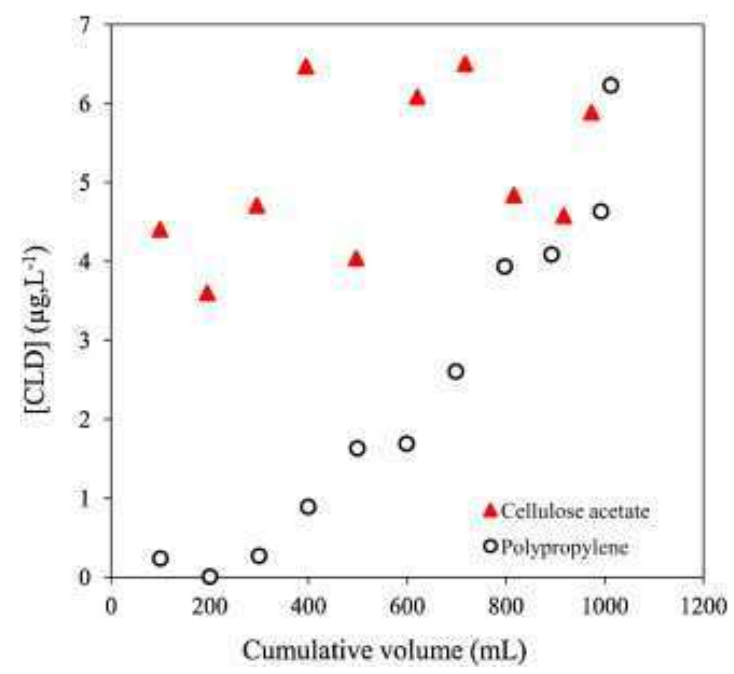

Fig. 2. Breakthrough curves of CLD through cellulose and polypropylene filters.

To avoid the CLD adsorption, the addition of methanol $(\mathrm{MeOH})$ or acetonitrile (ACN) as cosolvents was tested. Calibration curves with CLD concentration ranging from 5 to $100 \mu \mathrm{g} \mathrm{L}$ were prepared with different solvent composition and were analyzed by LC-MS/MS after CHP filtration ( $2 \mathrm{~mL}$ approx.). The addition of $50 \%$ (vol.) allowed the inhibition of CLD adsorption, the mean observed relative deviation on 4 samples filtered/unfiltered was lower than $10 \%$. Fig. $3 \mathrm{a}$ shows the calibration curves obtained for various solvent compositions. Although the addition of a co-solvent inhibited the adsorption of CLD onto membrane filters the use of high proportion of $\mathrm{ACN}$ or $\mathrm{MeOH}$ harmed to the chromatogram quality with an increasing width at half height of 
the CLD peak. This effect was commonly observed in reversed phase liquid chromatography when the solvent of injection contains a proportion of organic solvent higher than the eluent. The use of 50\% ACN was an interesting compromise allowing the limitation of adsorption and peak broadening.
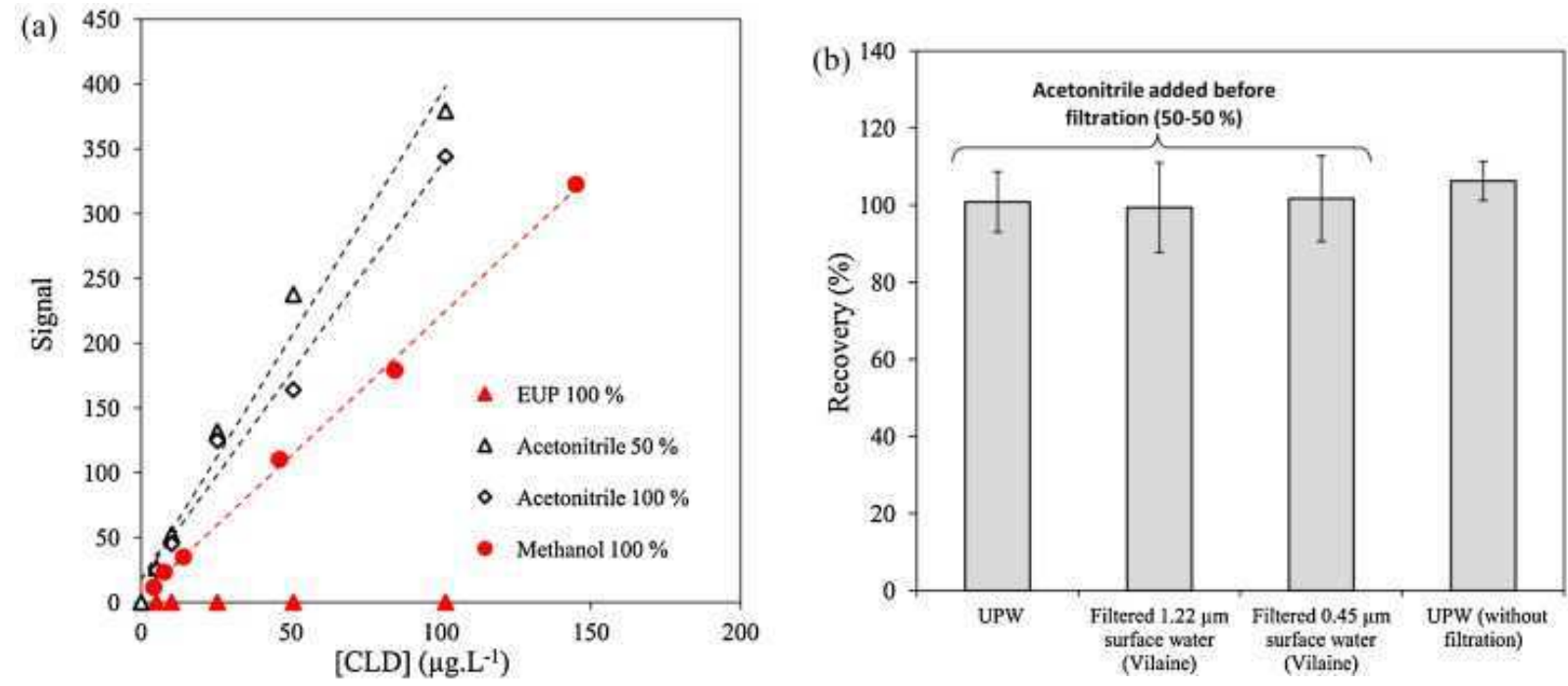

Fig. 3. (a) Calibration curves in various solvents; (b) influence of the DOM on the recovery of CLD.

\section{Effect of organic matter}

Because of its apolarity and low water solubility, a potential adsorption of CLD onto suspended matter and the formation of dissolved organic matter (DOM)-CLD complexes were suspected in surface water samples. In a previous work, Driscoll et al. have enlightened the formation of DOM-pesticides complexes with mirex and photo-mirex which possess similar chemical structures to CLD [33]. In the case of mirex and photo-mirex, the yield of liquid-liquid extraction with hexane used prior to the GC analysis was only $70 \%$. Consequently an additional step consisting of the DOM-pesticide complex destruction was needed prior to the analysis. The effect of suspended matter and DOM on the chlordecone determination was evaluated using surface water (Vilaine river, France) containing $5.3 \mathrm{mg}$ of dissolved organic carbon. $10 \mathrm{~mL}$ of filtered $(0.45 \mu \mathrm{m})$ and unfiltered surface water were spiked with CLD at $100 \mu \mathrm{g} \mathrm{L}^{-1}$ and equilibrated during $48 \mathrm{~h} .10 \mathrm{~mL}$ of $\mathrm{ACN}$ were added before the filtration and analysis. No significant differences were observed between the control sample (UPW) and surface water (Fig. 3b). So if a CLD-DOM complex was eventually formed, the use of ACN allowed the complex destruction and did not lead to any analytical bias. Moreover the CLD adsorbed on suspended matter was desorbed with ACN before the analysis. Consequently, the use of this sample preparation protocol allowed the determination of CLD in surface water and was not significantly affected by the presence of suspended matter nor the dissolved organic matter. 


\section{Effect of inorganic compounds}

Unlike the observations made on the quantification of chlordecone in surface water, a strong inhibition of the MS signal was observed in activated sludge supernatant samples spiked with CLD. Organic and/or inorganic compounds in this complex environmental matrix dramatically affect the determination of chlordecone. In order to identify the source of analytical bias, potential interference sources have been evaluated separately. A fresh activated sludge (AS) was centrifuged in order to separate the biomass from the supernatant, aqueous phase was then spiked with CLD $\left(1100 \mu \mathrm{g} \mathrm{L}^{-1}\right)$. Sample from cultivated AS containing inorganic nutritive solution (INS) was prepared using the same protocol. Fig. 4 shows the concentration of CLD determined in the aqueous phase of these samples; quantification was achieved by external calibration. In the absence of INS the measured signal for CLD in AS supernatant did not significantly differs from the control sample (UPW $1100 \mu \mathrm{g} \mathrm{L}^{-1}$ ). In the presence of INS the measured CLD concentration decreased to $50 \%$ of its theoretical value. So the interferences observed here were due to the inorganic fraction. The effect of each ion on the CLD determination was then evaluated separately by addition of the appropriate amount of salt into the CLD stock solution. Fig. 4 shows that each ion significantly affects the determination of CLD. Signal inhibition was particularly important with $\mathrm{CaCl}_{2}$ addition ([CLD $\left.]_{\text {mes }} /[\mathrm{CLD}]_{\mathrm{ref}}=0.42\right), \mathrm{KH}_{2} \mathrm{PO}_{4}$ and $\mathrm{NH}_{4} \mathrm{NO}_{3}$ also dramatically affected the MS signal. The effect of $\mathrm{NaH}_{2} \mathrm{PO}_{4}, \mathrm{MgSO}_{4}$ and trace metal solution (TMS) was rather limited but significant. The coelution of inorganic compounds with chlordecone may affect the ionization yield by ESI and leads to the formation of inorganic adducts not monitored in MRM acquisition mode.

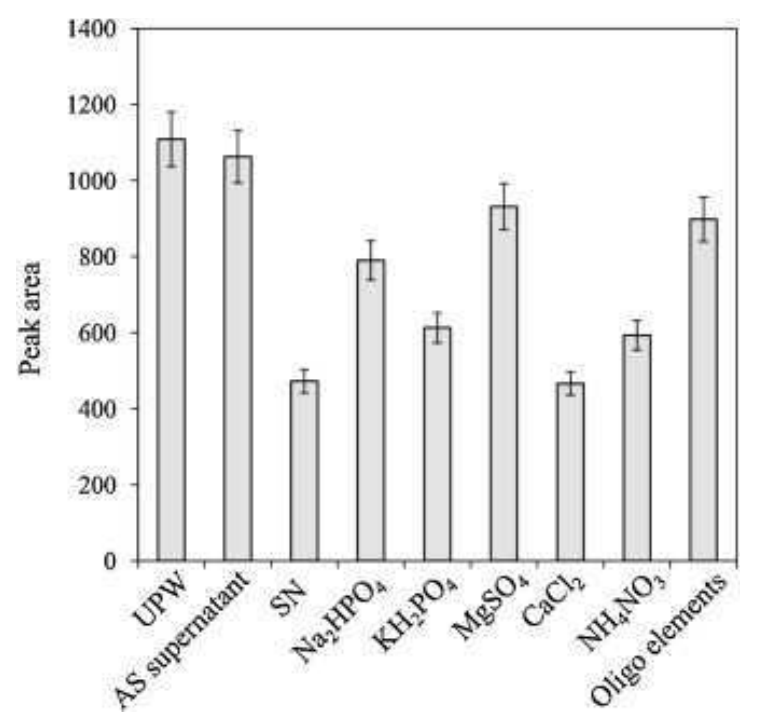

Fig. 4. Influence of inorganic compounds on the analysis of $C L D\left([C L D]_{0}=1 \mathrm{mg} \mathrm{L}^{-1}\right)$.

In spite of the very low retention factor of inorganic salt onto C18 column, high concentrations of salts may temporarily contaminated the MS interface and explained the presence of salt in the 
electrospray at the retention time of CLD. So some analytical conditions were tested to delay the CLD peak and to allow the elimination of salts before the elution of CLD.

In a first approach LC was performed with solvent A (ACN-FA, 999:1, v/v) and solvent B (UPW-ACN-FA, 900:99:1, v/v) in isocratic mode (70\% A-30\% B). This composition containing a high proportion of strong solvent (ACN) decreased the peak broadening, minimized the analysis time and was found as the optimal solvent for CLD ionization in the interface. However these conditions led to a limited retention of CLD into the analytical column (retention time: $\mathrm{RT}=1.3 \mathrm{~min}$, retention factor: $k=1.17$ ). In order to increase the retention factor of CLD and limit the slats interferences, different compositions of mobile phase were studied in isocratic mode. As shown in Fig. 5, the retention factor increased from $k=0.66$ at UPW $=18 \%$ (vol.) to $k=10.3$ at UPW $=54 \%$ (vol.). The use of solvent composition containing high water proportion $(A: B, 40: 60, v / v)$ led to the best separation of the minerals and the CLD. Indeed, for this composition no significant differences were observed between the CLD in UPW and the CLD solution containing the INS. Fig. 5 illustrates the effect of water content on the area of CLD peak spiked or not with INS. An increase of the water content allowed reducing the observed differences between CLD in UPW and CLD in saline solution. A minimum of 50\% solvent A (UPW 45\%) was needed to eliminate inorganic interferences. Nevertheless the increasing retention factor also rose the CLD peak width and reduced the ionization efficiency, due to the high proportion of water, in the ESI interface which leads to a significant increase of the limit of quantification (LOQ). In order to avoid the interferences without compromising on the LOQ, the separation was performed with a binary gradient according to the following program: maintaining $40 \%$ A during 2 min followed by a linear gradient from $40 \%$ A to $70 \%$ A in 1 min; maintaining $70 \%$ A from 3 to $5 \mathrm{~min}$, returning linearly to $40 \% \mathrm{~A}$ in $0.1 \mathrm{~min}$ and equilibrating from 5.1 to $6 \mathrm{~min}$. Under these conditions, retention time for CLD was $3.88 \mathrm{~min}(k=5.5)$ and the elution of CLD was performed at solvent composition of $70 \%$ A which enable optimal ionization without interferences caused by salts.
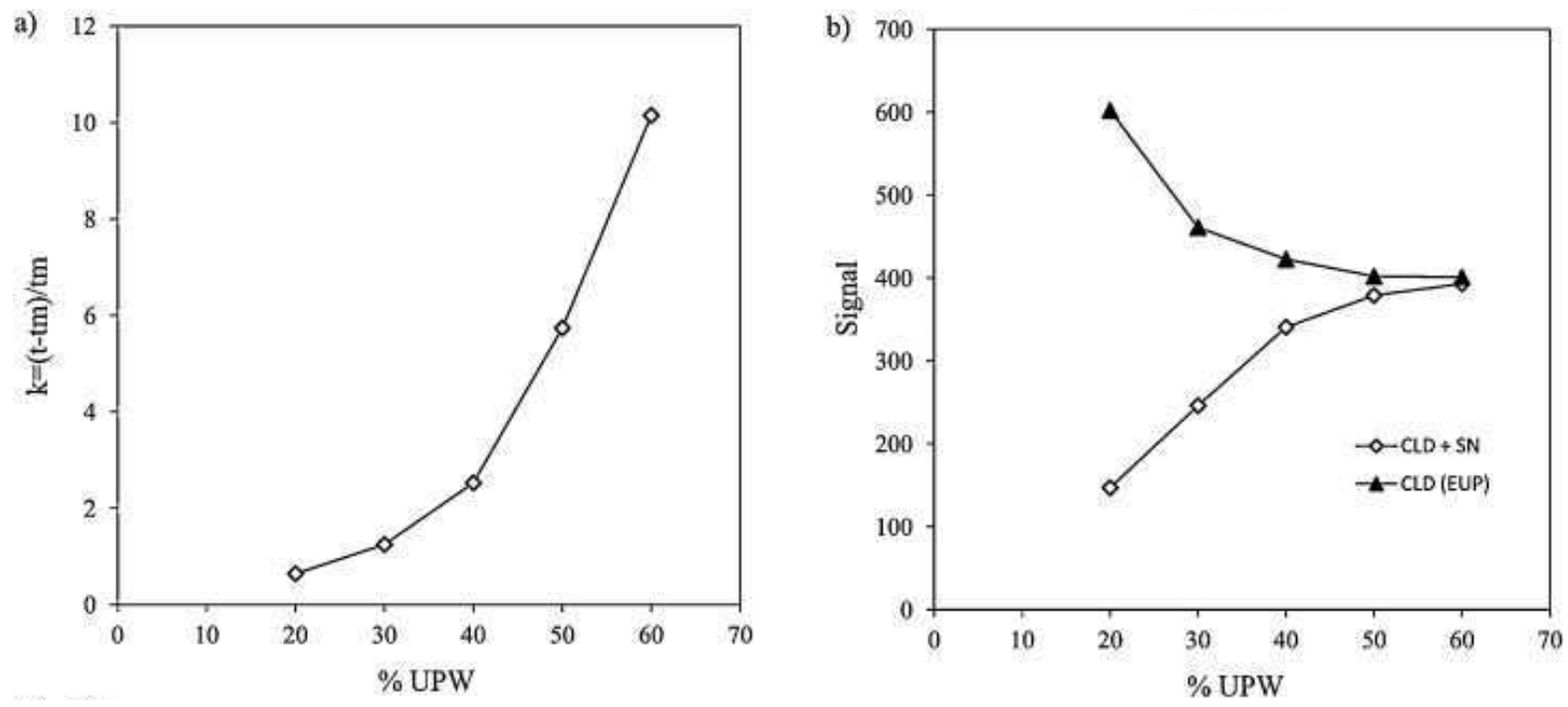
Fig. 5. Influence of the composition of the solvent on the retention times (a) and on the area of the peaks $(b)$.

\section{Validation method}

Calibration curves of chlordecone were achieved using different environmental matrix: UPW, drinking water, surface water and supernatant of activated sludge which represent the more complex aqueous matrix studied here. Standard solutions were prepared by dilution of CLD stock solution $\left(1000 \mu \mathrm{g} \mathrm{L}{ }^{-1}\right.$ in $\left.\mathrm{ACN}\right)$ in the considered matrix, solution were homogenized and $10 \mathrm{~mL}$ was added to $10 \mathrm{~mL}$ of ACN before filtration and analysis. Fig. 6 demonstrates the linearity of MS response over this range with a confidence interval of 95\% (Fig. 6). The slopes of calibration curves obtained in the various tested matrix were similar $\left(1.54-2.37 \mathrm{~L} \mathrm{\mu g}^{-1}\right)$ but significantly differed each relative to the others. So the use of a calibration curve established on the same matrix than the sample appeared to be needed in order to accurately quantify CLD. The performance of analytical method was assessed with statistical tests in order to validate the linear regression model and to deduce the limit of detection and quantification (LOD and LOQ, respectively) for chlordecone according to the French regulation (AFNOR NF-T-90-210):

$$
\begin{gathered}
L O D=\frac{y_{0}+3 \sigma_{y_{0}}}{a} \\
L O Q=\frac{y_{0}+10 \sigma_{y_{0}}}{a}
\end{gathered}
$$

where $a, y_{0}$ and $\sigma \mathrm{y}_{0} \sigma \mathrm{y} 0$ represent the slope of the calibration curve, the intercept and the standard deviation on the intercept, respectively. Under the analytical conditions developed here, LOQ ranged from 6 to $11 \mu \mathrm{g} \mathrm{L}^{-1}$. The LOD-LOQ obtained using this statistical approach depended on the number and the position of the standard level. In order to make possible the quantification of CLD at concentration lower than $10 \mu \mathrm{g} \mathrm{L}^{-1}$, specific calibration curves were determined in a restricted range $\left(0.1-10 \mu \mathrm{g} \mathrm{L}^{-1}, n=9\right)$. The slope and intercept of lowconcentration curves thus obtained were similar to values observed in the full-range. For example, considering activated sludge supernatant the full-range slope and intercept were $1.99 \mathrm{~L} \mathrm{\mu g}^{-1}$ and 1.88 while low-range slope was $2.00 \mathrm{~L} \mathrm{\mu g}^{-1}$ and 1.76 , respectively. Given the minimization of slope standard deviation with the low-concentration calibration curve, the LOQ was decreased. As an example the LOQ in activated sludge supernatant calculated with full-range calibration was $6.1 \mu \mathrm{g} \mathrm{L}^{-1}$ was lowered to $1.5 \mu \mathrm{g} \mathrm{L}^{-1}$ using low-range calibration. 
a)

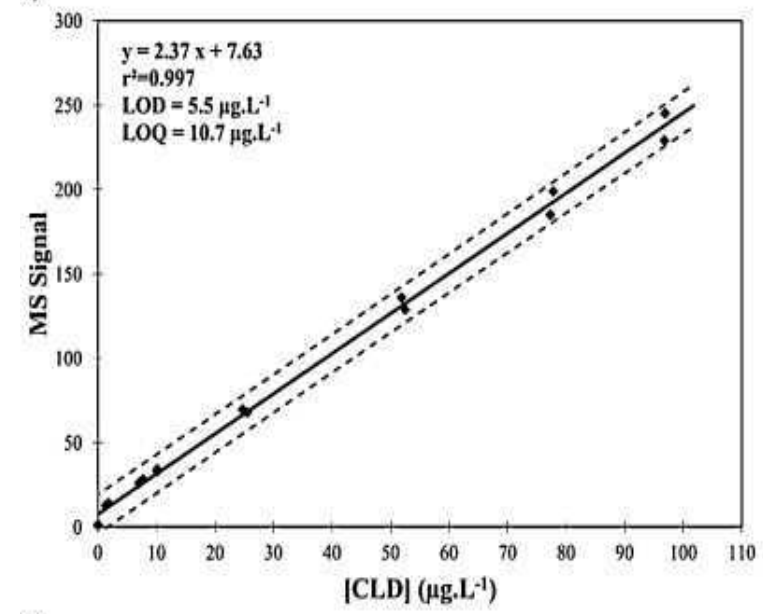

c)

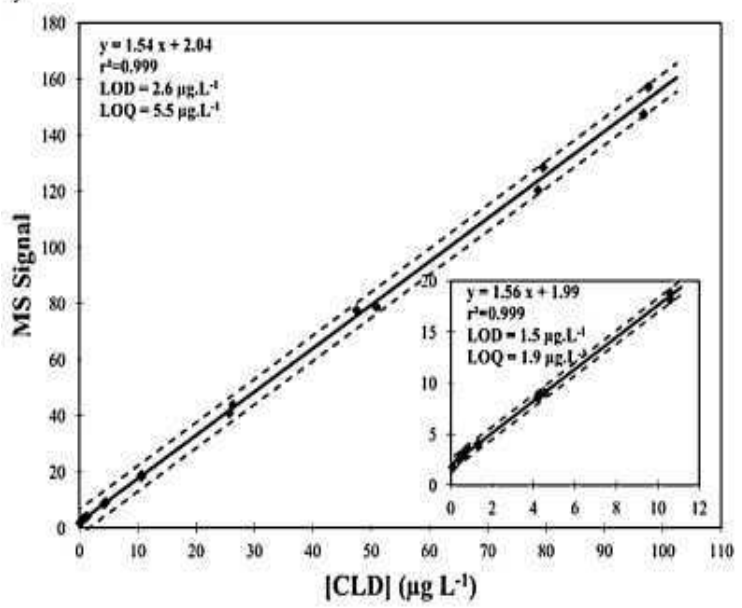

b)

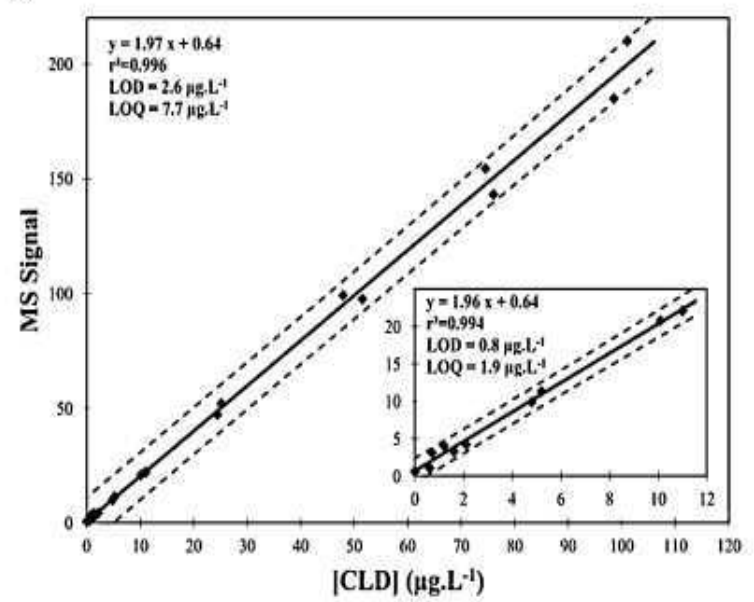

d)

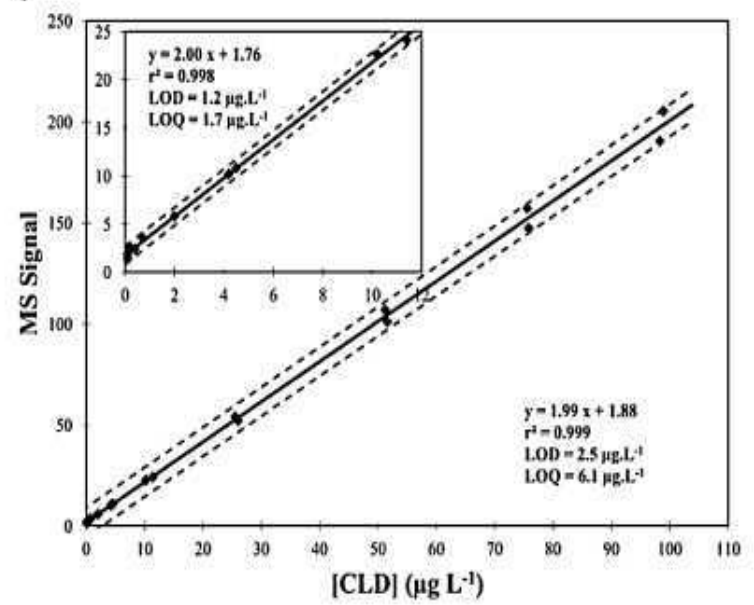

Fig. 6. Calibration curves of chlordecone in different environmental matrix: (a) UPW, (b) drinking water, (c) surface water, and (d) supernatant of activated sludge.

\section{Chlordecone analysis in activated sludge}

The determination of total CLD concentration in biological system need to take into account the fraction adsorbed into biomass and free aqueous fraction in the supernatant. A simple protocol for CLD speciation was developed here using autoclaved biomass to avoid any biodegradation of CLD. As illustrated in Fig. 7, $5 \mathrm{~mL}$ of sample from bioreactor was centrifugated (5 min; $4000 \mathrm{rpm}$ ) to separate biomass from supernatant. CLD concentration in the supernatant ([CLD $]_{\mathrm{aq}}$ ) was quantified by pipetting $4 \mathrm{~mL}$ of the liquid phase followed by the addition of $4 \mathrm{~mL} \mathrm{ACN}$ before filtration and LC-MS/MS analysis. The remaining supernatant was eliminated and the extraction of CLD associated with biomass was achieved using a mixture of UPW:ACN (50:50, $\mathrm{v}: \mathrm{v})$. After $1 \mathrm{~mL}$ of vortex homogenization, the sample was centrifugated, filtered and analyzed ([CLD $\left.]_{\text {bio }}\right)$. The yield of extraction was calculated using the initial concentration in the spiked sample $\left([\mathrm{CLD}]_{0}=1100 \mu \mathrm{g} \mathrm{L^{-1 }}\right)$ according to: 
Extraction Yield $(\%)=100 \frac{\frac{2[C L D]_{a q}}{V_{0}}+\frac{[C L D]_{b i o}}{V_{2}}}{\frac{[C L D]_{0}}{V_{0}}}$

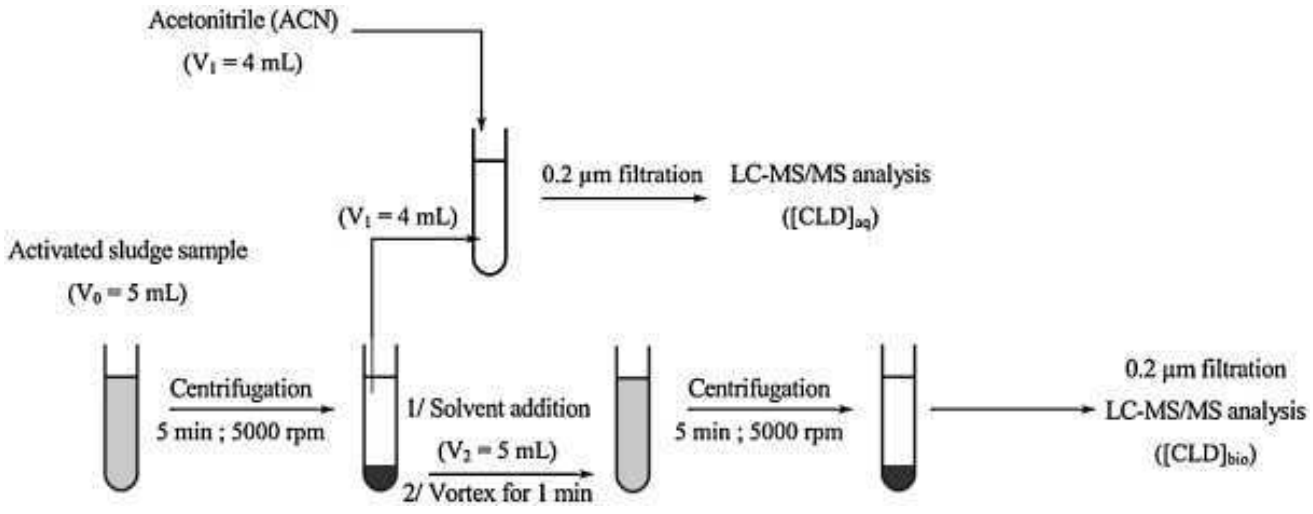

Fig. 7. Extraction protocol for chlordecone speciation in activated sludge sample.

Extraction of chlordecone from biomass was evaluated on 5 autoclaved activated sludge sample spiked with CLD $\left([C L D]_{0}=1100 \mu \mathrm{g} \mathrm{L}^{-1}\right.$; biomass $\left.=1 \mathrm{~g} \mathrm{~L}^{-1}\right)$. Fig. 8 shows the yield of extraction and the speciation of chlordecone in activated sludge. These results demonstrate a satisfactory recovery yield and standard deviation $(95 \pm 5 \%)$. The use of ultrasonic extraction did not increase the extraction yield $(101 \pm 4 \%)$.

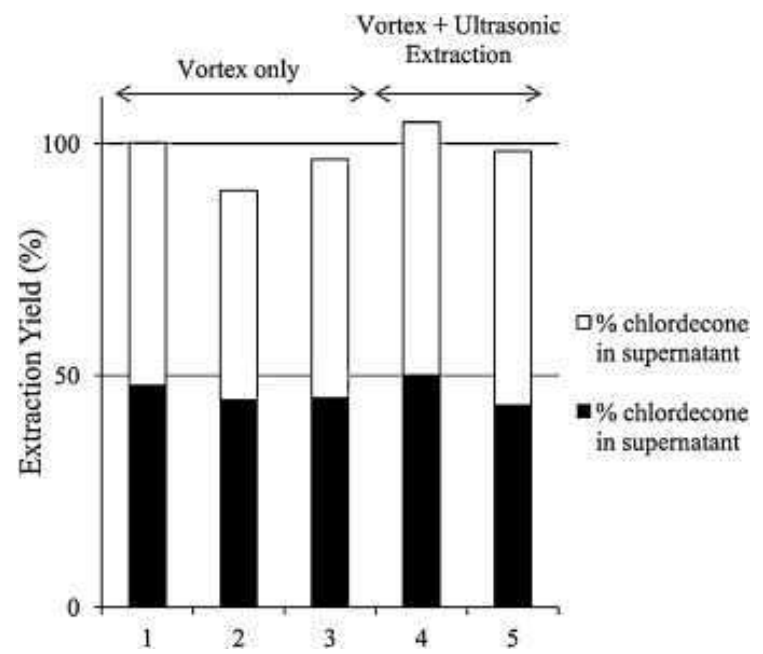

Fig. 8. Extraction of the chlordecone and speciation in activated sludge.

A complete desorption was thus obtained with the extraction by ACN, which is a solvent more apolar than water. Then, CLD should not be chemically adsorbed and its adsorption onto 
activated sludge may probably involve low energies interactions, such as Van der Walls forces or hydrophobic interactions.

\section{Sorption}

\section{Kinetics}

Sorption kinetics were carried out for a contact time of 20 min with $1 \mathrm{mg} \mathrm{L}^{-1}$ CLD to $0.5 \mathrm{~g} \mathrm{~L}^{-1}$ inactivated sludge and are displayed in Fig. 9. CLD sorption was a fast process, since $85 \%$ sorption was achieved in less than 5 min (Fig. 9).

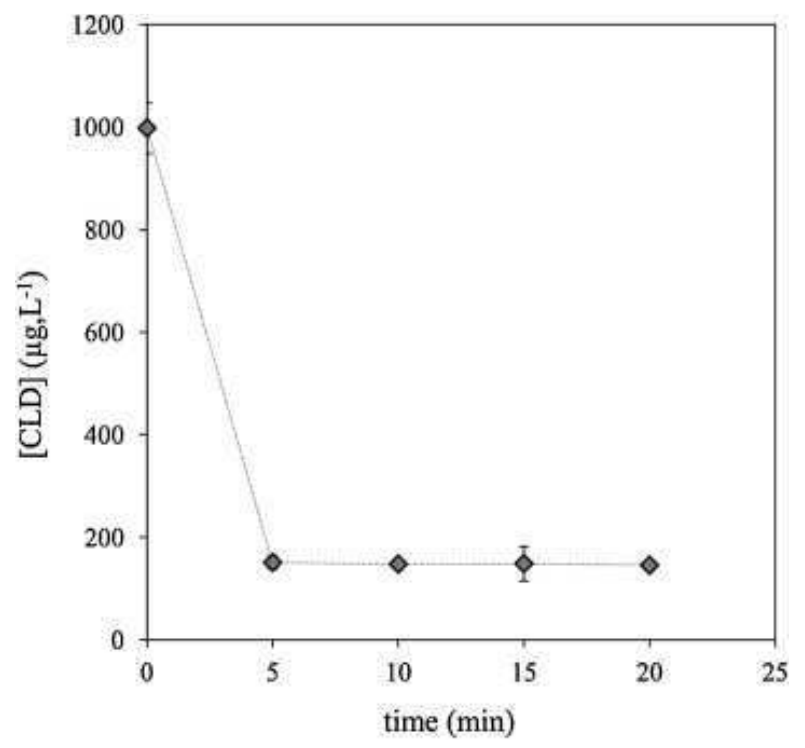

Fig. 9. Time-course of CLD biosorption on activated sludge.

\section{Equilibrium isotherms}

They were performed for inactivated sludge concentrations in the range $25-500 \mathrm{mg} \mathrm{L}^{-1}$ in contact with $1 \mathrm{mg} \mathrm{L}^{-1} \mathrm{CLD}$ at $25^{\circ} \mathrm{C}$. Adsorption capacity at equilibrium was determined according to the following equation:

$$
q_{e}=\frac{C_{0}-C_{e}}{C_{A S}}
$$

With $q_{e}$ the equilibrium adsorption capacity ( $\mu \mathrm{g} \mathrm{mg}_{\mathrm{dry}}$ weight ${ }^{-1}$ ), $C_{0}$ and $C_{e}$ the initial and equilibrium CLD concentrations respectively $\left(\mu \mathrm{g} \mathrm{L}^{-1}\right), C_{A S}$ the sludge concentration $\left(\mathrm{g} \mathrm{L}^{-1}\right)$. The errors on the adsorption capacity were assessed using the assumption of the propagation of uncertainty. 
The experimental results at equilibrium are shown in Fig. 10 and put forward the linear relationship between the amount of adsorbed CLD and its concentration in solution at equilibrium. The solid/liquid partition coefficient for CLD $\left(\mathrm{L} \mathrm{g}^{-1}\right)$ can be therefore determined according to:

$$
K_{O C}=\frac{C_{S}}{C_{e}}
$$

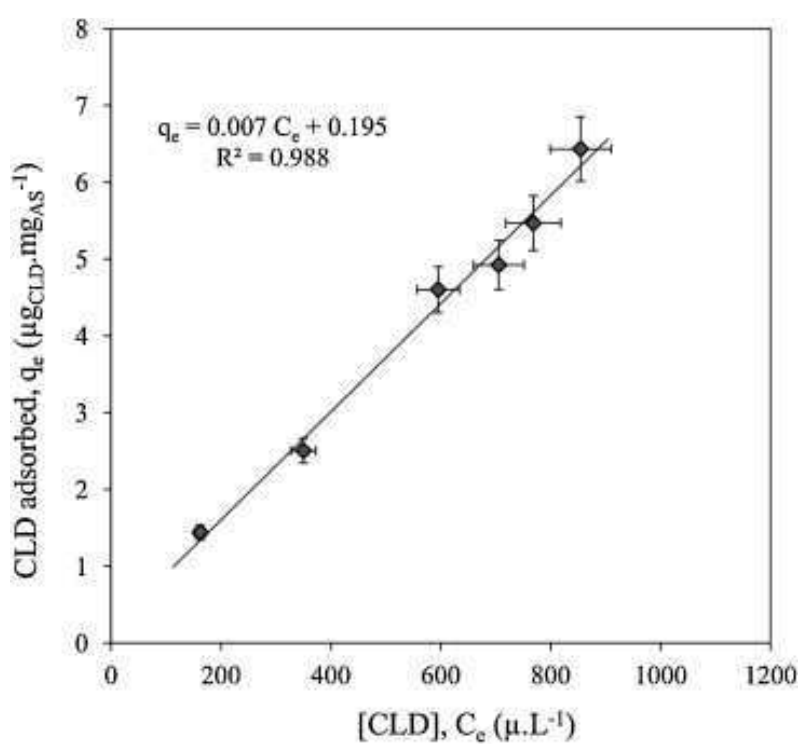

Fig. 10. Isotherm of CLD biosorption on activated sludge.

With $C_{S}$ the CLD concentrations in the solid (sludge) $\left(\mathrm{mg} \mathrm{kg}^{-1}\right)$ phase at equilibrium.

The $K_{\mathrm{OC}}$ value was found to be $7600 \mathrm{~L} \mathrm{~kg}^{-1}$, leading to a $\log K_{\mathrm{OC}}$ of 3.88 , which is in the order of magnitude of the values found in the literature. For instance, $\log K_{\mathrm{OC}}$ of 3.3 was determined in soils, rich in organic matter [34]. Therefore, a similar sorption behavior was observed on the organic matter from soil, rather hydrophobic, and onto (inactivated) sludge even if the microbial organic matter was more hydrophilic. The solid/liquid partition coefficient can be therefore assumed not to be a function of the nature of the organic matter.

\section{Conclusion}

A method for CLD analysis by LC/MS/MS has been developed and validated and, then, an extraction procedure of CLD from activated sludge was established. These two protocols enabled the study of CLD sorbed onto activated sludge. Kinetics and sorption isotherms of CLD were examined. Sorption kinetics showed a fast adsorption of CLD, less than $5 \mathrm{~min}$. Benefiting from this fast adsorption, the amount of CLD that could be adsorbed was linearly dependent on the bulk concentration. Thus, the partition coefficient from the liquid to solid phases was $K_{\mathrm{OC}}=7600 \mathrm{~L} \mathrm{~kg}^{-1}$, which was equivalent to $\log K_{\mathrm{OC}}=3.88$. This value was in the same order of 
magnitude as the coefficients determined in soils rich in organic matter. Hydrophobic interactions were thus confirmed.

\section{References}

[1] G.W. Dawson, W.C. Weimer, S.J. Shupe, Kepone - A case study of a persistent material, The American Institute of Chemical Engineers (AIChE) Symposium Series. 75 (1979) 366-374.

[2] J.Y. Le Deaut, C. Procaccia, Les pesticides aux Antilles : bilan et perspectives d'évolution, Office Parlementaire d'Evaluation des Choix Scientifiques et Technologiques; 2009.

[3] G. Bocquene, A. Franco, Pesticide contamination of the coastline of Martinique, Mar. Pollut. Bull. 51 (2005) 612-619.

[4] R.L. Harris, R.J. Huggett, H.D. Slone, Determination of dissolved kepone by direct addition of XAD-2 resin to water, Anal. Chem. 52 (1980) 779-780.

[5] F.Y. Saleh, G.F. Lee, Analytical methodology for kepone in water and sediment, Environ. Sci. Technol. 12 (1978) 297-301.

[6] R. Moseman, H. Crist, T. Edgerton, M.K. Ward, Electron capture gas chromatographic determination of Kepone residues in environmental samples, Arch.f Environ. Con. Tox. 6 (1977) 221-231.

[7] S.A. Ornoff, R.R. Colwell, Microbial transformation of kepone, Appl. Environ. Microb. 39 (1980) 398-406.

[8] H.V. Brewerton, D.A. Slade, Kepone residues on apples, New Zeal. J. Agr. Res. 7 (1964) 647-653.

[9] R.V. Blanke, M.W. Fariss, F.D. Griffith, P. Guzellan, Analysis of chlordecone kepone in biological specimens, J. Anal. Tox. 1 (1977) 57-62.

[10] N. Mady, D. Smith, J. Smith, C. Wezwick, Analysis of kepone in biological samples, National Bureau of Standards Special Publication. 519 (1979) 341-343.

[11] M.J. Vidal, M.M. Frias, G.A. Frenich, F. Olea-Serrano, N. Olea, Determination of endocrinedisrupting pesticides and polychlorinated biphenyls in human serum by GC-ECD and GC-MS-MS and evaluation of contributions to the uncertainty of the results, Anal. Bioanal. Chem.372 (2002) 766-775.

[12] R. Húšková, E. Matisová, S. Hrouzková, L. Švorc, Analysis of pesticide residues by fast gas chromatography in combination with negative chemical ionization mass spectrometry, J. Chromatogr. A. 1216 (2009) 6326-6334.

[13] G.F. Pang, Y.M. Liu, C.L. Fan, J.J. Zhang, Y.Z. Cao, X.M. Li, Z.Y. Li, Y.P. Wu, T.T. Guo, Simultaneous determination of 405 pesticide residues in grain by accelerated solvent extraction then gas chromatography-mass spectrometry or liquid chromatography-tandem mass spectrometry, Anal. Bioanal. Chem. 384 (2006) 1366-1408. 
[14] S. George, L. King, L. Claxton, High-performance liquid chromatography separation of chlordecone and its metabolites, Chromatographia. 22 (1986) 165-167.

[15] A. Durimel, S. Altenor, R. Miranda-Quintana, P. Couespel Du Mesnil, U. Jauregui-Haza, R. Gadiou, S. Gaspard, pH dependence of chlordecone adsorption on activated carbons and role of adsorbent physico-chemical properties. Chem. Eng. J. 229 (2013) 239-249.

[16] J.M. Sulfita, A. Horowitz, D.R. Shelton, J.M. Teidje, Dehalogenation: a novel pathway for the anaerobic biodegradation of haloaromatic compounds. Sci. 218 (1982) 1115-1117.

[17] A. Bianchi, Déchloration réductrice du perchloroéthylène et du trichloroéthylène à l'aide d'un residu industriel riche en magnétite incorporé à une émulsion huile dans eau. Université du Québec à Montréal, 2009.

[18] L. Moretti, ln situ bioremediation of DNAPL Source Zones, US Environmental Protection Agency, Office of Solid Waste and Emergency Response, Technology Innovation and Field Services Division, 2005.

[19] L. Prat, Identification and characterization of proteins supporting dehalorespiration in desulfitobacterium hafniense strain TCE1. Ecole Polytechnique Fédérale de Lausanne, 2009.

[20] J. Dolfing, I. Novak, A. Archelas, H. Macarie, Gibbs Free Energy of Formation of Chlordecone and Potential Degradation Products: Implications for Remediation Strategies and Environmental Fate, Environmental Science \& Technology, 46 (2012), pp. 8131-8139

[21] G.N. Schrauzer, R.N. Katz, Reductive dechlorination and degradation of mirex and kepone with vitamin B12, Bioinorg. Chem. 9 (1978) 123-143.

[22] H. Smidt, W.M. De Vos, Anaerobic microbial dehalogenation, Annu. Rev. Microbiol. 58 (2004) 4373.

[23] P.E. Jablonski, D.J. Pheasant, J.G. Ferry, Conversion of kepone by methanosarcina thermophila, FEMS Microbiol. Lett. 139 (1996) 169-173.

[24] K. Chojnacka, Biosorption and bioaccumulation: the prospects for practical applications, Environ. Int. 36 (2010) 299-307.

[25] K. Vijayaraghavan, Y.S. Yun, Bacterial biosorbents and biosorption, Biotechnol. Adv. 26 (2008) 266-291.

[26] Y.H. Ju, T.C. Chen, J.C. Liu, A study on the biosorption of lindane, Colloid. Surface. B. 9 (1997) 187-196.

[27] M. Tsezos, J.P. Bell, Comparison of the biosorption and desorption of hazardous organic pollutants by live and dead biomass, Water Res. 23 (1989) 561-568.

[28] P. Benoit, E. Barriuso, R. Calvet, Biosorption characterization of herbicides, 2,4-D and atrazine, and two chlorophenols on fungal mycelium, Chemosphere. 37 (1998) 1271-1282. 
[29] Z. Ning, K.J. Kennedy, L. Fernandes, Biosorption of 2,4-dichlorophenol by live and chemically inactivated anaerobic granules, Water Res. 30 (1996) 2039-2044.

[30] Z. Aksu, Application of biosorption for the removal of organic pollutants: a review, Process Biochem. 40 (2005) 997-1026.

[31] H. Moriwaki, A. Hasegawa, Detection of chlordecone by liquid chromatography with tandem mass spectrometry, Rapid Commun. Mass Sp. 18 (2004) 1243-1244.

[32] A. Picot, M. Rabache, Fiche toxico écotoxico-chimique ${ }^{\circ} 3$, Association toxicologique - CNAM, 2005 .

[33] M.S. Driscoll, J.P. Hassett, C.L. Fish, Extraction efficiencies of organochlorine compounds from Niagara river water, Environ. Sci. Technol. 25 (1991) 1432-1439.

[34] S. Colombano, C. Blanc, V. Guerin, B. Chevrier, Examen des possibilites de traitement de la chlordecone dans les sols notamment sur les aires d'alimentation des captages d'eau potable, BRGM, 2009. 